\title{
Project-Based Learning and Self Directed Learning
}

\section{Davidoff, Katja $^{a}$ and Piñeiro, Carol ${ }^{\mathrm{a}}$}

${ }^{\mathrm{a} C e n t e r}$ for English Language and Orientation Programs, Boston University, Boston, Massachusetts, USA

\begin{abstract}
This article discusses the benefits of project-based and self-directed learning to develop competency in utilizing a second language and working collaboratively. The background premise of these modes of learning is provided, demonstrating that they work well for differentiated levels and language skills and improve student competence. Some of the areas examined are intercultural and scientific, ones that require the use of specific language in context. In addition, the concept of creating projects that increase student investment and motivation to make learning more relevant is juxtaposed with a student's competency in an area after having participated in traditional approaches to learning. The overall benefit of the use of project-based and self-directed learning is that it allows the student to develop a higher skill set and greater engagement with the subject matter, producing better language and content outcomes.
\end{abstract}

Keywords: Project-based learning; self-directed learning; intercultural communication; STEM; third space. 


\section{Introduction}

Project-Based Learning and collaborative work is becoming more commonplace in teaching practice. Project-based learning (PBL) lends itself well to the incorporation of technology, prevalent in our everyday lives. With PBL, students can use technological and online resources available to research, investigate, and work collaboratively. Additionally, technology allows for both autonomous and collaborative work, enabling students to succeed at their own pace and potentially avoid conflicts of perspective while researching varying contexts, and finally providing them with a medium to connect their material with other students.

The multimodal uses of technology give learners of varying levels and thought patterns a chance to learn and investigate before establishing relationships with other students. The ability of a student to work in congruence with his or her own personal style creates a comfort level to enable better cooperation on group projects. The use of projects is thought to aid students' learning to become more personally relevant and thus increase their acquisition of knowledge and generation of new meanings in the target language. It has been conjectured that projects enable students to utilize language in meaningful ways and that the inherent relevance of the material facilitates more efficient acquisition of skills that students can transfer to other contexts. This is in contrast with more traditional teaching practice, assumed to teach skills in set patterns, but not necessarily in connection with the semantic schema of the student, and also focused upon content rather than a student's learning process.

\section{Theoretical Framework of Self-Directed and Project-Based Learning}

The premise of Self-Directed Learning Theory is that the student learns how to learn by self-monitoring his or her own progress and attending to his or her own metacognitive skills involved in the learning process (Zimmerman \& Schunk 2008). The skill set employed by Project-Based Learning and its inherent principles crosses over into the skill set utilized in self-directed learning and vice versa.

Project-based learning follows constructivist theory by allowing students to approach context and generate personal meaning in relation to that context via inquiry and research (Krajcik \& Blumenfeld 2004). The following items are the principal steps of project-based learning (Blumenfeld et al.1991; Krajcik, et al. 1994; Czerniak \& Berger 2002, p. 2). 
1. They start with a driving question, a problem to be solved.

2. Students explore the driving question by participating in authentic, situated inquiry- processes of problem solving that are central to expert performance in the discipline. As students explore the driving question, they learn and apply important ideas in the discipline.

3. Students, teachers, and community members engage in collaborative activities to find solutions to the driving question. This mirrors the complex social situation of expert problem solving.

4. While engaged in the inquiry process, students are scaffolded with learning technologies that help them participate in activities normally beyond their ability.

5. Students create a set of tangible products that address the driving question. These are shared artifacts, publicly accessible external. Representations of the class's learning.

Collaborative learning with a focus on contextual project allows for students to surpass differences of learning style and to find a niche for particular abilities in working with a group. Student engagement with the material in a personally meaningful way, allows for deeper understanding and connection with the material being studied.

\subsection{Mutual Understanding and Intercultural Communication Project}

Due to past experiences of cultural misunderstandings and difficulty maintaining collaboration when teaching mixed classes of students, as well as a lack of awareness of the harmful effects of stereotyping, creating any kind of group work or project requiring cooperation proved difficult. Even when the students did respect those from other cultures, misunderstandings arose from dissimilar premises of how to solve a problem or what process one should use to investigate and solve it. Some students had little or no experience developing research and dialogic inquiry skills.

The following paradigm was created in an attempt to encourage students to work collaboratively and to lay aside their preconceived notions of others in the class. Students were given both a problem to research and a task to carry out. Students in an adult ESL/EFL class were paired with another from a different culture and language base. Most of the students ranged in age from 17-25, with some outliers in the age range of 25-50. If students were from the same country, then each one was paired with someone from a different town, religious base, or cultural heritage. Students were given a rubric requiring research, evidence of investigative skills, and a presentation. The basic task, (basic so that it could be adjusted for student level and proficiency), was for each student to research as much as possible about the home culture of their partner, albeit with a caveat. First, students worked collaboratively to create questions about their partner's home culture. 
Once the questions were agreed upon as a whole class, and once students had a chance to object to anything too personal or uncomfortable to answer, students started by researching their partners' home culture via the Internet and other resources.

After all research is gathered, the partner then presents his or her research to the partner of that home culture. The partner then informs the partner conducting the research of any information that does not apply to his or her personal life and culture. After the partner has chosen the applicable aspects of home culture, he or she then teaches the researcher how these aspects apply to personal and daily life and explains anything not well understood. The partner records information for his or her presentation. The same process is then followed in reverse with the other partner.

On the day of presentations, students follow a rubric they were given to show what points to cover and in what manner. The crucial finale to the exercise is that students can only present what their partner has approved, thereby avoiding guessing, stereotyping, misunderstanding, and conjecture. The presenting student can only present what is relevant and true in their partner's home culture. This project has been done with three different classes: one low intermediate, one intermediate, and one advanced intermediate. All research was conducted in the second or target language.

\subsection{STEM Project on the Lifecycle of Plastics}

Similar to the steps outlined in the description of intercultural communication, the ProjectBased Learning approach also works effectively in other areas of education such as Science, Technology, Engineering, and Math, or STEM as it is currently referred to. Many university intensive English programs not only teach ESL/EFL, they also provide specialized courses like English for Business, Law or Science and Technology. It is the last area, Sci-Tech, that will be the focus of the following section.

The students in these courses have as their aim to enter undergraduate or graduate Sci-Tech programs in U.S. universities. They come from a variety of countries and cultures, and STEM becomes the "third space" as mentioned by Homi Bhabha (2006), or a hybrid between two cultures or histories. While this term is applied loosely here, it can be imagined as the overlapping space of two or more circles in a Venn diagram. The students from different countries or cultures are those circles, and the area in which they overlap is their interest in and passion for science. It is this space that unites them in a Sci-Tech program and the impetus that drives them to find a real-world problem and search for a creative and viable solution.

The five steps introduced in the Theoretical Framework are the same ones that are followed in PBL in the sciences. This constructivist approach allows students to identify, explore, engage, collaborate, research, and finally, arrive at a solution as a group. An example of a 
STEM project done in a class of adult ESL/EFL learners at an advanced level was one on the lifecycle of plastic. It began with a question about why students at the language center threw their plastic containers into the trash can instead of the recycling bin. The students were divided into groups of 3-4 of mixed linguistic and cultural backgrounds. After discussing the topic, they decided on several ways to address this question. As a class, they first devised a survey to administer to other students at the language center to find out why they didn't recycle their items and administered it to 5 students each in their free time. Then they combined the results and found that the main reason was that students didn't know what could be recycled because the sign on the bin simply said "Recycle".

One group decided to look at the university's website as their second step and found a "Sustainability" page https://www.bu.edu/sustainability/ that explained what could be recycled, how much waste the university produced each year, and how much they had begun to save by initiating sustainable practices. Another group visited the dining hall in the student union and saw that recycling stations were clearly labeled and got the idea that the same could be done at the language center. Yet another group looked at the trash pickup areas and saw that the trash and recyclable items were clearly separated so that they could be collected and properly disposed of. In this stage of the project, students were participating in "authentic, situated inquiry processes of problem-solving" as noted in the Theoretical Framework.

The third stage of the project was to find solutions to their question by engaging in collaborative activities. One group wrote to the Office of Sustainability and to ask if a speaker could come to class to talk about the topic. There happened to be student volunteers for just such a purpose, and one agreed to come and talk about the myriad ways that students could save energy and resources as well as the ways the university was trying to do so. After his talk, the groups decided to make recycling signs so that other students could understand exactly what materials could be put in the bin. They also made a personal commitment not to buy water in plastic bottles, but to use their own containers and refill them from the purified water stations around the university. After looking online for clip art, each group made graphic visuals that delivered a clear message about what could be recycled. They laminated the signs and asked other teachers at the language center if they could give a five-minute talk about recycling in their classes, which most welcomed with enthusiasm. The signs that the students fastened on the recycle bins and the talks they gave to their peers served as publicly shared artifacts and visible representations of the students' learning.

Finally, each group did a research project on where the plastic goes if it is not recycled. One group spoke about the trash heaps in certain countries where the poorest of the poor go to scavenge. Another spoke about the ocean gyres and the objects that float in them and the tiny pieces of degraded plastic that fish and birds ingest. Yet another spoke about the 
unsightly trash heaps on riverbanks and seashores that contaminate waterways and prevent people from enjoying nature. On a positive note, one group spoke about "plastic fashion", or the use that artists and designers are making of recycled materials.

Although some of the students had been strangers to each other at the beginning of the term, by the end of this PBL cycle, which lasted approximately six weeks, they were very close. Because they had thought of a question that was part of their daily lives at the language center and taken steps to research it collaboratively at the university level, they felt empowered. When they had learned enough to make a decision to act upon their new knowledge, both by changing their personal behavior and by educating their fellow classmates, they felt like they were indeed part of the scientific community. They had collaborated on different aspects of inquiry, searched for answers from knowledgeable sources, generated their own solutions, and disseminated both the knowledge they had acquired and the solutions they had arrived at to a wider audience.

\section{Conclusion}

The intercultural project yielded excellent results in all three classes, based on student selfreport and feedback to others in the class. During the presentations, the listening partners expressed positive emotion and pleasure with how they were represented, and how much their partners had learned about their home and life. Students were surprisingly respectful and humorous when dealing with unknown facts, and some even chose to give a mini language lesson during their presentations. Of note from a pedagogical point of view was the overall cohesion of the class, the increase in fluency and participation in class discussions, as well as the recall of the research conducted.

After these presentations, students appeared more bonded and earnestly invested in maintaining a positive class atmosphere. The assumption is that the effort to understand and portray another's culture in such an enthusiastic and deferential manner raised the expectations of classroom culture and offered a chance for students to actually "see" their classmates from the others' point of view.

In addition, the project allowed for adjusted pace of varying levels of target language proficiency in the class and in addition, made the language acquired as well as the learning process personally relevant. An added bonus was the increasing awareness of students' metacognition and the research process. Because students are sometimes forced to work in groups or with partners with poor results, this project allowed students to work independently at first, adjust their pace, and further develop mindfulness of themselves as learners before working collaboratively. The students had ample opportunity to selfregulate and to further these skills in meeting the goals and deadline of the project. 
The STEM project also helped the students to bond through shared inquiry into a problem identified by the group, interactive research online and at the university, and collaborative generation of solutions that were shared and publicized. The acquisition of specialized scientific vocabulary from Internet searches and readings, contact with university offices and representatives, and deeper research into their chosen topics was much more effective than learning lists of lexical items for later testing. During their final presentations, they were teaching each other about a related yet unknown topic, which generated enthusiasm on the part of both the speakers and listeners.

During this PBL cycle, the students felt as if they were acting like scientists by driving the process of inquiry forward on their own initiative. Some students have kept in touch with the instructor and each other as they moved on to different universities in the U.S. to become real scientists who will find actual solutions to current problems and improve life on earth.

In contrast to project-based learning, classes where more traditional methods of teaching are used, the classroom dynamics are more related to and reflective of the dominant and subordinate personalities of students and the perception of the dominant culture. When students work in pairs for short exercises or even take part in discussions, they never seem to develop positive rapport and collaborative skills, unless they learn to respect and care about each other outside of class. The use of projects, in particular ones that increase awareness of identity and purpose and provide opportunities to bond and progress, appear to make a great difference in class dynamics, motivation to learn, and development of proficiency in a language.

\section{References}

Bhabha, H. (2006) Cultural Diversity and Cultural Differences. The Post-Colonial Studies Reader. B. Ashcroft, G. Griffiths, H. Tiffin (Eds.) New York: Routledge, 155-157.

Kim, S. U. (2012). A Research Project Helps Immigrant Students Plan Their EducatioN. Knowledge Quest , 40(3), 49-53. http://doi:10.1787/888933422839

Kingsley, K. V., \& Kingsley, K. (2009). A case study for teaching information literacyskills. BMC Medical Education, 9, 7. http://doi.org/10.1186/1472-6920-9-7

Krajcik, J., S., Blumenfeld, P.C. (2006). The Cambridge Handbook of Learning Sciences. New York: NY. Cambridge University Press. Ch. 19.

Steinke, K. (2012): Implementing SDL as Professional Development in K-12. International Forum of Teaching and Studies 8.1, 54-63. ProQuest. Web. 30 Jan. 2017.

Taylor, P. C. Cultural Hybridity and Third Space Science Classrooms. Cultural Studies of Science Education 1(1), 189-195.

Zarei, A. A., and Keshavarz, J. M.A. (2011). On The Effects of Two Models of Cooperative Learning on EFL Reading Comprehension and Vocabulary 
Learning." Modern Journal of Language Teaching Methods 1.2, 39-54. ProQuest. Web. 30 Jan. 2017.

Zimmerman, B. J. (2002). Becoming a Self-Regulated Learner: An Overview. Theory Into Practice, 41(2), 64-70. doi:10.1207/s15430421tip4102_2 